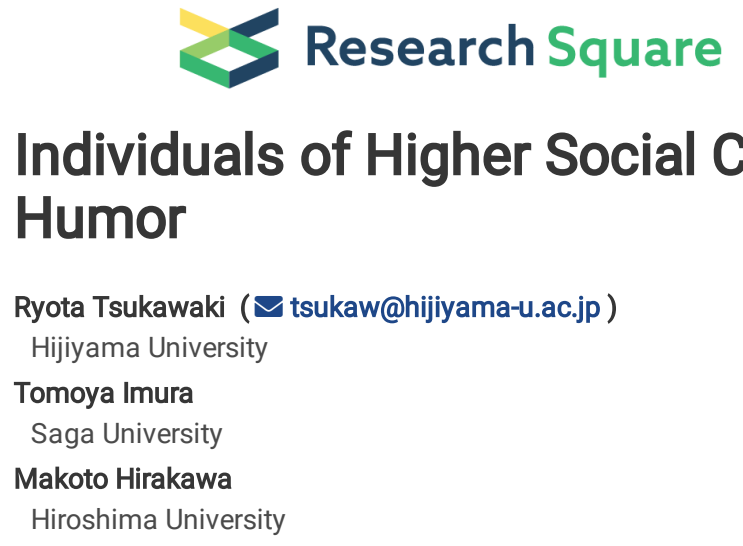

Ryota Tsukawaki ( $\nabla$ tsukaw@hijiyama-u.ac.jp )

Hijiyama University

Tomoya Imura

Saga University

Makoto Hirakawa

Hiroshima University

\title{
Individuals of Higher Social Class Engage in Other-Oriented and Adaptive Humor
}

Research Article

Keywords:

Posted Date: February 21st, 2022

DOI: https://doi.org/10.21203/rs.3.rs-1356456/v1

License: (-) (1) This work is licensed under a Creative Commons Attribution 4.0 International License. Read Full License 


\section{Abstract}

Previous research on individual social class (SC) and humor has found support for the hypothesis that those with higher SC engage in dominant and selfish humor (aggressive humor). This hypothesis is based on the well-known theory that people with high SC are selfish, but there are mixed findings regarding this theoretical perspective. In this study, SC was measured by objective measures (income and educational attainment) and subjective measures (perceived social status) and examined in relation to humor. Previous research on SC and humor has been limited, focusing only on the limited dimensions of humor (aggressive and affiliative humor). In the present study, four types of humor assessed by the Humor Styles Questionnaire and two types of humor measured by the Dual Self-Directed Humor Scale were taken into account to learn more about the relationship between SC and humor. Study 1 ( $N=344)$ and Study 2 $(N=604)$ consistently showed that SC and aggressive humor are not related, and the findings of previous studies were not replicated. Rather, SC was shown to be positively associated with adaptive humor, such as other-oriented humor and humor for coping with stress.

\section{Introduction}

\subsection{Social class and prosociality}

Social class (SC) has a multifaceted structure consisting of both objective characteristics ${ }^{1}$, such as material wealth and access to resources, and subjective perception $^{2}$ of one's position within the social hierarchy ${ }^{3}$. Since 2010 , individuals with high SC have been reported to be selfish, to be self-centered, and to have low prosociality ${ }^{4,5}$. The most famous study was a series of experiments by Piff et al. ${ }^{5}$, who reported that individuals with high SC - measured in terms of subjective measures and objective measures such as income and education - were less likely to engage in a variety of prosocial behaviors. The study showed that individuals with high SC did not give points that would later be exchanged for money to anonymous partners in the dictator game, did not prefer to donate to charity, did not give points to assigned strangers in the trust game, and did not help experimental partners in need more than individuals with low SC.

Furthermore, the results showed that people with high SC were not only less likely to engage in prosocial behavior but also more likely to engage in a variety of unethical selfish behaviors ${ }^{6,7}$. As a representative study, a series of experiments by Piff et al. ${ }^{7}$ revealed that people with high SC, as measured mainly by subjective indicators and objective indicators such as owning vehicles, were more likely to break the law while driving, steal valuable goods from others, lie in negotiations, commit fraud to increase the likelihood of winning prizes, and take unethical actions in the workplace (increase sales by, for example, making personal long-distance calls at work or overcharging customers) than people with low SC. Other studies showed that people with a high SC, in contrast to those with a low SC, had a lower characteristic score for compassion ${ }^{8}$; inaccurate emotional reasoning related to others ${ }^{9}$; more behaviors that indicate a lack of attention to others, such as playing with one's hands and doodling when interacting with strangers ${ }^{10}$; and a tendency to engage in humor to control others ${ }^{11}$.

However, the results from Piff et al. ${ }^{5,7}$, a representative study showing low prosociality in people with high SC, have often not been supported by subsequent replication studies. Korndörfer et al. ${ }^{12}$ found that people with a high SC (measured by subjective indicators and objective indicators such as income and education) were more charitable, helpful, and likely to volunteer than those with a low SC and were more cooperative in trust games in a large and representative international sample. To test whether the findings reported by Piff et al. ${ }^{5,7}$ could be reproduced, preregistered exact replication studies were performed by Stamos et al. ${ }^{13}$ and Balakrishnan et al. ${ }^{14}$. However, the relationship between SC and prosocial action and unethical action was not reproduced; rather, the individuals with high SC carried out prosocial action more often, and unethical action was not carried out. In addition, many studies ${ }^{15-18}$ have shown results that conflict with those of Piff et al. ${ }^{5,7}$, and in recent years, the finding that people with high SC are more social than those with low SC appears to have become dominant. Thus, the findings of representative studies showing low prosociality in people with high $\mathrm{SC}^{5,7}$ have been rejected, raising questions about the reliability of the findings on the association between SC and other indicators associated with prosociality (e.g., dominant humor and compassion).

In the current study, we focused on the relationship between SC and humor and introduced a new hypothesis by theorizing their association from a different perspective from those considered in previous studies. The objective was then to test the hypotheses by examining the relationship between humor and people's SC as assessed by objective (i.e., income and educational attainment) and subjective (i.e., perceived social status) indicators.

\subsection{Humor}

Martin et al. ${ }^{19}$ conceptualized humor as a multidimensional structure with both adaptive and maladaptive components. The theory distinguishes between two adaptive types of humor (affiliative and self-enhancing humor) and two maladaptive types (aggressive and self-defeating humor). Those with high affiliative humor are more likely to be other-oriented and to tell jokes to entertain others and develop interpersonal relationships, while those with high selfenhancing humor are more likely to maintain a humorous view of life even in adversity. People with high aggressive humor tend to use sarcasm and teasing frequently to dominate others, and people with high self-defeating humor tend to use humor directed at themselves excessively to gain approval from others. Martin et al. ${ }^{19}$ developed an instrument, the Humor Styles Questionnaire (HSQ), to distinguish and assess these four types of humor, and the HSQ is the most widely used instrument in research on individual differences in humor ${ }^{20}$.

Recently, Tsukawaki and Imura ${ }^{21}$ pointed out a problem with the self-defeating humor scale, a subscale of the HSQ. This scale measures individual differences in the use of self-directed humor (SDH), but it focuses only on its inappropriate dimension. However, Tsukawaki and Imura ${ }^{21}$ argued that famous theorists of the past ${ }^{22,23}$ and contemporary researchers ${ }^{24,25}$ have emphasized the adaptive aspect of SDH. Adaptive SDH relates to humor to distance oneself from the problems one is facing and to downplay stressful events. This type of SDH can address fears and anxieties arising from problems in a

Page 2/10 
positive way by allowing the individual to laugh at the problems faced. Along these lines, Tsukawaki and Imura ${ }^{21}$ developed the Dual Self-Defeating Humor Scale (DSDHS), the first instrument to assess individual differences in SDH use from two dimensions, positive and negative. Initial validation of the DSDHS has provided promising evidence of reliability and validity 21,26 .

\subsection{SC and humor}

Navarro-Carrillo et al. ${ }^{11}$ examined the association between humor and SC assessed by subjective indicators and objective indicators such as income and educational attainment. In their study, they hypothesized that SC is negatively correlated with affiliative humor and positively associated with aggressive humor based on theories that emphasize the self-centered and selfish tendencies of people with high SC ${ }^{27,28}$. The results on SC and aggressive humor support this hypothesis and show that people with high SC engage in selfish and controlling humor. However, given the relatively small sample size of this study ( $N=156$ for Study 1 and $N=201$ for Study 2 ) and the recent rejection of representative studies ${ }^{5,7}$ revealing low prosociality in those with high SC, the reliability of this hypothesis and result is questionable. Furthermore, research findings that individuals with high SC are less aggressive ${ }^{29,30}$ also call into question this hypothesis and the results. Therefore, we propose a new hypothesis regarding the association between SC and humor from a health behavior perspective.

Health behavior comprises the behavior patterns, actions and habits that relate to health maintenance, health restoration and health improvement ${ }^{31}$. There are many actions that can be classified as impacting health, such as smoking, diet, exercise, and alcohol use. The relationship between SC and health behaviors is an active research topic, and researchers have generally agreed that people with high SC are more engaged in healthy behaviors (e.g., physical activity, healthy diet) and less engaged in unhealthy behaviors (e.g., smoking, early sexual activity) ${ }^{32-38}$. The HSQ and DSDHS, which are instruments for assessing an individual's humor, were developed to focus on the type of humor that is thought to be most associated with an individual's well-being ${ }^{19,21}$. Subsequently, the HSQ was widely used in hundreds of studies to examine its association with health indicators; a meta-analysis by Schneider et al. ${ }^{39}$ summarized the relationship between the HSQ and health and found that, in general, affiliative humor and self-enhancing humor are adaptive and aggressive humor and self-defeating humor are maladaptive, supporting the initial findings ${ }^{40}$. The DSDHS is an instrument that was only recently developed, but to date, it has shown promising results, with deleterious SDH being detrimental to psychological health and benign SDH being beneficial ${ }^{21,26}$. Therefore, humor, as assessed by the two scales, can be considered a health behavior because of its well-established link to health. Again, given that people with high SC engage in healthier behaviors and less unhealthy behaviors, we argue that high levels of SC are positively correlated with adaptive humor and negatively correlated with maladaptive humor.

\subsection{Present study}

The current study proposes and tests a new hypothesis about the relationship between SC and humor: previous research on SC and humor ${ }^{11}$ was limited to using only some subscales of the HSQ (affiliative and aggressive humor) to assess individual humor. We considered four types of humor as measured by the HSQ and two types of humor as assessed by the DSDHS to broadly capture the multidimensional structure of humor. Of the four types of humor assessed by the HSQ, adaptive humor (affiliative and self-enhancing) is positively associated with psychological and physical health, while maladaptive humor (aggressive and self-defeating) is associated with the opposite pattern ${ }^{19}$. Therefore, we proposed the following hypotheses about the relationship between SC and HSQ:

\section{Hypothesis 1}

There is a positive association between SC and adaptive humor (affiliative and self-enhancing) as measured by the HSQ.

\section{Hypothesis 2}

There is a negative association between SC and maladaptive humor (aggressive and self-defeating) as measured by the HSQ.

Next, among the two types of SDH assessed by the DSDHS, benign SDH has been shown to be positively associated with psychological health, while deleterious SDH has been shown to be negatively associated with psychological health ${ }^{21,26}$. From this, we formed the following hypotheses between SC and DSDHS:

\section{Hypothesis 3}

There is a positive association between SC and benign SDH.

\section{Hypothesis 4}

There is a negative association between SC and deleterious SDH.

In Study 1, we tested our hypotheses by measuring individual SC by an objective measure, household income. In Study 2, which was conducted to extend Study 1, SC was measured in a multidimensional way from the objective measures of household income and educational attainment and the subjective measure of one's perceived social status to test the hypotheses.

\section{Study 1}

\subsection{Method}




\subsubsection{Participants and procedure}

The participants in Study 1 consisted of 344 adults (209 males and 135 females), all of whom were Japanese. The mean age was 48.41 years (SD = 9.88), and the age range was 21-74 years. These participants were provided by Freeasy (https://freeasy.research-plus.net/lp/), a leading Japanese online research service operated by iBRIDGE Co., Ltd. Potential participants were notified of the questionnaire by e-mail from Freeasy. Of these people, those who provided informed consent responded via the Internet in their free time.

\subsubsection{Measures}

All participants completed the HSQ (Martin et al. ${ }^{19}$; Japanese version by Yoshida ${ }^{41}$ ) and the DSDHS ${ }^{21}$ to assess individual differences in humor. In addition, the participants provided their household's annual after-tax income as an objective measure of SC.

The HSQ ${ }^{19}$ is a 32 -item scale for assessing individual differences in four types of humor: affiliative, self-enhancing, aggressive, and self-defeating. The sample items are "I enjoy making people laugh" (affiliative), "If I am feeling depressed, I can usually cheer myself up with humor" (self-enhancing), "If I don't like someone, I often use humor or teasing to put them down" (aggressive), and "I will often get carried away in putting myself down if it makes my family or friends laugh" (self-defeating). Each subscale consists of 8 items and is rated on a 7-point Likert scale ranging from 1 (totally disagree) to 7 (totally agree). Cronbach's alpha values in this study ranged from 0.82 to 0.91 .

The DSDHS ${ }^{21}$ is a scale for assessing individual differences in the two dimensions of SDH (deleterious and benign SDH). This is a 10 -item scale with 5 items in each subscale. The sample items include the following: "I try to find a place for myself in my friendships by making a fool of myself to make my friends laugh" (deleterious SDH) and "I honestly accept problems I can't solve and end up laughing about them with my family and friends" (benign SDH). A sevenpoint Likert scale ranging from 1 (totally disagree) to 7 (totally agree) was employed to rate the items. The Cronbach's alpha values in this study were 0.82 for "deleterious SDH" and 0.85 for "benign SDH".

Finally, household income, an objective measure of SC, was assessed in the following 15 categories: (a) less than 1 million yen, (b) 1 to 2 million yen, (c) 2 to 3 million yen, (d) 3 to 4 million yen, (e) 4 to 5 million yen, (f) 5 to 6 million yen, (g) 6 to 7 million yen, (h) 7 to 8 million yen, (i) 8 to 9 million yen, (j) 9 to 10 million yen, (k) 10 to 12 million yen, (I) 12 to 15 million yen, (m) 15 to 18 million yen, (n) 18 to 20 million yen, and (o) 20 million yen or more.

\subsubsection{Data analysis}

In the preliminary analysis, means and standard deviations were calculated for all study variables. In addition, a frequency analysis was conducted for household income, an objective measure of SC. Intercorrelations between humor and SC were calculated by zero-order correlational analyses. Finally, we examined the partial correlation between humor and SC using age and gender as control variables, similar to Navarro-Carrillo et al. ${ }^{11}$, which examined the association between humor and SC. Gender was coded as a dummy variable ( $0=$ male, $1=$ female). SPSS 27 was used for these analyses.

\section{1. 4. Approval For Human Experiments}

An ethical approval was obtained from Ethical Committee of Graduate School of Education, Saga University for the study. All methods were carried out in accordance with relevant guidelines and regulations. All participants provided online informed consent prior to being monitored.

\subsection{Results and discussion}

The means and standard deviations of the humor and SC measures are shown in Table 1. The distribution of participant income was as follows: less than 1 million yen (8.7\%), 1 to 2 million yen (6.1\%), 2 to 3 million yen (11.6\%), 3 to 4 million yen (12.2\%), 4 to 5 million yen (10.8\%), 5 to 6 million yen (10.8\%), 6 to 7 million yen (9.3\%), 7 to 8 million yen (6.7\%), 8 to 9 million yen (3.8\%), 9 to 10 million yen (5.8\%), 10 to 12 million yen (5.5\%), 12 to 15 million yen (4.4\%), 15 to 18 million yen $(0.9 \%), 18$ to 20 million yen (1.2\%), and more than 20 million yen $(2.3 \%)$. 
Table 1

Means, SDs, and zero-order correlations among study variables.

\begin{tabular}{|c|c|c|c|c|c|c|c|}
\hline & 1. & 2. & 3. & 4. & 5. & 6. & 7. \\
\hline 1. AFH & - & $0.30 * \star \star$ & -0.04 & 0.03 & 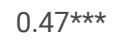 & $-0.19 \star \star \star$ & $0.25^{\star \star \star}$ \\
\hline 2. SHE & & - & 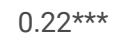 & $0.54 * \star \star$ & $0.63^{\star \star \star}$ & $0.38 * \star \star$ & 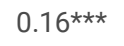 \\
\hline 3. AGH & & & - & $0.51^{\star \star \star}$ & $0.13^{\star}$ & $0.48^{\star \star \star}$ & 0.05 \\
\hline 4. SDH & & & & - & $0.42^{\star \star \star}$ & $0.72^{\star \star \star}$ & 0.07 \\
\hline 5. BSDH & & & & & - & $0.44^{\star \star \star}$ & $0.18^{\star \star}$ \\
\hline 6. DSDH & & & & & & - & -0.01 \\
\hline 7. Income & & & & & & & - \\
\hline$M$ & 4.31 & 3.74 & 3.33 & 3.37 & 3.65 & 2.91 & 6.09 \\
\hline$S D$ & 0.99 & 0.90 & 0.92 & 1.07 & 1.28 & 1.34 & 3.53 \\
\hline \multicolumn{8}{|c|}{$\begin{array}{l}\text { Note. } N=344 \text {. AFH, affiliative humor; SEH, self-enhancing humor; AGH, aggressive humor; SDH, self-defeating humor; DSDH, deleterious SDH; BSD } \\
\text { benign SDH; M, mean; SD, standard deviation. }\end{array}$} \\
\hline \multicolumn{8}{|l|}{${ }^{\star} p<0.05$} \\
\hline \multicolumn{8}{|l|}{${ }^{*} p<0.01$} \\
\hline$\star \star \star p<0.001$ & & & & & & & \\
\hline
\end{tabular}

Table 1 shows that SC is significantly positively correlated with affiliative humor, self-enhancing humor, and benign SDH. No significant correlations were found between other types of humor and SC. Finally, we conducted a partial correlation analysis between SC and humor, controlling for age and gender, and the results were similar to those of the single correlation analysis. The results were similar to those of the single-correlation analysis, although significant positive correlations were found between SC and affiliative humor $\left(r_{\text {partial }}=.26\right)$, self-enhancing humor $\left(r_{\text {partial }}=.26\right)$, and benign SDH $\left(r_{\text {partial }}=.18\right)(p S<.01)$. No significant associations were found with the other types of humor $\left(r_{\text {partial }}<.08, p s\right.$. $\left.>15\right)$.

These results support hypotheses 1 and 3 but not hypotheses 2 and 4 . This means that individuals with high SC tend to use adaptive humor, but there is no difference between people with high and low SC in the use of maladaptive humor. It is important to note that the results are in contrast to those of a previous study by Navarro-Carrillo et al. ${ }^{11}$. They reported that SC and affiliative humor are uncorrelated, but there is a significant positive correlation between SC and aggressive humor. However, our data showed a significant positive correlation between SC and affiliative humor, while SC and aggressive humor were unrelated. In Study 2, we will measure SC in a more multidimensional way and examine whether the results are replicated.

\section{Study 2}

\subsection{Method}

\subsubsection{Participants and procedure}

Study 2 included 607 adult Japanese participants (340 males and 267 females). The mean age was 49.53 years (SD = 12.23), and the age range was $22-91$ years. These participants were recruited into the study in the same manner as in Study 1.

\subsubsection{Measures}

As in Study 1, all participants completed the HSQ and DSDHS to assess individual differences in humor and selected household income from 15 categories as an objective measure of SC. Cronbach's alphas on each humor scale were adequate in Study 2 (as >0.82). In addition, in Study 2, the participants also reported educational attainment, which was used as an objective measure of SC, and the MacArthur Scale of Subjective Socioeconomic Status ${ }^{2}$, which was used as a subjective measure.

Educational attainment was divided into six categories: (a) junior high school graduate, (b) high school graduate, (c) associate's degree (vocational/vocational training or academic), (d) bachelor's degree, (e) master's degree, and (f) doctoral degree.

We used the MacArthur Scale of Subjective Socioeconomic Status ${ }^{2}$, which we translated into Japanese. In this scale, the participants are presented with a graphic 10-step ladder representing ascending positions based on income, education level, and occupation and report their SC position in society in general by selecting a step on the ladder.

\subsubsection{Data analysis}

First, means and standard deviations were calculated for all study variables. Next, frequency analyses were conducted for household income and educational attainment, which are objective measures of SC. Intercorrelations between humor and SC were calculated by zero-order correlational analyses. Finally, a hierarchical multiple regression analysis was performed to determine the predictive value of each SC measure for each type of humor. Before 
performing this analysis, each SC scale was standardized, and collinearity statistics were calculated to ensure that the recommended value (VIF < 5,

Akinwande et $a l .{ }^{42}$ ) was not exceeded (VIFs $\left.<1.25\right)$. In the hierarchical multiple regression analysis, age and gender were included as control variables in the first step. In the second step, household income, educational attainment, and subjective SC were entered. For these analyses, SPSS 27 was used.

\subsection{Results and discussion}

The means and standard deviations of the humor and SC measurements are shown in Table 2. The distribution of the participants' income was as follows: less than 1 million yen (5.9\%), 1 to 2 million yen (8.6\%), 2 to 3 million yen (11.2\%), 3 to 4 million yen (15.7\%), 4 to 5 million yen (11.2\%), 5 to 6 million yen (10.5\%), 6 to 7 million yen (8.6\%), 7 to 8 million yen (7.9\%), 8 to 9 million yen (3.6\%), 9 to 10 million yen (4.4\%), 10 to 12 million yen (4.6\%), 12 to 15 million yen (3.5\%), 15 to 18 million yen (1.6\%), 18 to 20 million yen (0.3\%), and more than 20 million yen (2.3\%). The distribution of educational attainment was as follows: junior high school graduate (2.5\%), high school graduate (28.7\%), associate's degree (20.4\%), bachelor's degree (43.3\%), master's degree (4.3\%), and doctoral degree $(0.8 \%)$.

Table 2

Means, SDs, and zero-order correlations among study variables.

\begin{tabular}{|c|c|c|c|c|c|c|c|c|c|}
\hline & 1. & 2. & 3. & 4. & 5. & 6. & 7. & 8. & 9. \\
\hline 1. AFH & - & $0.40 * \star \star$ & 0.10 & $0.25^{\star \star \star}$ & 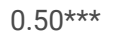 & -0.02 & $0.25^{\star \star \star}$ & 0.02 & $0.26^{\star \star \star}$ \\
\hline 2. SHE & & - & $0.10 *$ & $0.28 * \star \star$ & $0.56^{\star \star \star}$ & $0.15^{\star \star \star}$ & $0.14^{\star \star \star}$ & 0.05 & $0.22^{\star \star \star}$ \\
\hline 3. AGH & & & - & 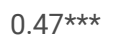 & $0.08^{*}$ & $0.42^{\star \star \star}$ & 0.03 & -0.04 & 0.01 \\
\hline 4. SDH & & & & - & $0.30 * \star \star$ & $0.68^{* * *}$ & -0.02 & -0.08 & 0.00 \\
\hline 5. BSDH & & & & & - & $0.25^{\star \star \star}$ & $0.13^{\star \star}$ & 0.01 & $0.18^{\star \star \star}$ \\
\hline 6. DSDH & & & & & & - & -0.02 & -0.06 & $-0.09 *$ \\
\hline 7. Income & & & & & & & - & $0.23^{\star \star \star}$ & $0.41^{* \star *}$ \\
\hline 8. Education & & & & & & & & - & $0.24^{\star \star \star}$ \\
\hline 9. SSC & & & & & & & & & - \\
\hline$M$ & 4.50 & 3.64 & 3.00 & 3.06 & 3.70 & 2.45 & 5.92 & 4.21 & 4.59 \\
\hline$S D$ & 1.22 & 0.91 & 0.97 & 1.13 & 1.29 & 1.28 & 3.37 & 1.01 & 1.98 \\
\hline \multicolumn{10}{|c|}{$\begin{array}{l}\text { Note. } N=607 \text {. AFH, affiliative humor; SEH, self-enhancing humor; AGH, aggressive humor; SDH, self-defeating humor; DSDH, deleterious SDH; BSDH, } \\
\text { benign SDH; SSC, subjective social class M, mean; SD, standard deviation. }\end{array}$} \\
\hline \multicolumn{10}{|l|}{${ }^{\star} p<0.05$} \\
\hline \multicolumn{10}{|l|}{$\star \star x p<0.01$} \\
\hline$\star * \star p<0.001$ & & & & & & & & & \\
\hline
\end{tabular}

In the zero-order correlation analysis shown in Table 2, household income and subjective SC were positively correlated with all types of adaptive humor (affiliative humor, self-enhancing humor, benign SDH). Hierarchical multiple regression analysis showed that subjective SC significantly predicted all adaptive humor; household income, an objective measure of SC, significantly predicted only affiliative humor, but educational attainment was unrelated to all types of humor (Table 3). The American Psychological Association ${ }^{43}$ argues that rather than integrating objective measures of SC, such as income and educational attainment, it is more useful to understand how each contributes to the outcome under study, and the data in this study support this view. 
Table 3

Hierarchical multiple regression analysis to predict six types of humor.

\begin{tabular}{|c|c|c|c|c|c|c|c|c|c|c|c|c|}
\hline \multicolumn{3}{|c|}{ Affiliative } & \multicolumn{2}{|c|}{ Self-enhancing } & \multicolumn{2}{|c|}{ Aggressive } & \multicolumn{2}{|c|}{$\begin{array}{l}\text { Self- } \\
\text { defeating }\end{array}$} & \multicolumn{2}{|c|}{$\begin{array}{l}\text { Deleterious } \\
\text { SDH }\end{array}$} & \multicolumn{2}{|c|}{ Benign SDH } \\
\hline Predictor & $\Delta R^{2}$ & $\beta$ & $\Delta R^{2}$ & $B$ & $\Delta R^{2}$ & $\beta$ & $\Delta R^{2}$ & $B$ & $\Delta R^{2}$ & $\beta$ & $\Delta R^{2}$ & $\beta$ \\
\hline Step 1 & 0.01 & & 0.00 & & 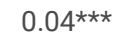 & & $0.01 *$ & & $0.01^{*}$ & & 0.00 & \\
\hline Age & & 0.01 & & 0.01 & & -0.15 & & -0.08 & & $-0.12^{\star \star}$ & & -0.01 \\
\hline Gender & & $0.10 *$ & & 0.01 & & $-.019 \star \star \star$ & & 0.05 & & -0.05 & & 0.04 \\
\hline Step 2 & 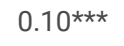 & & $0.05^{\star \star \star}$ & & 0.01 & & 0.01 & & 0.01 & & $0.04^{\star \star \star}$ & \\
\hline Age & & 0.02 & & 0.02 & & -0.15 & & -0.09 & & $-0.12^{\star \star}$ & & 0.00 \\
\hline Gender & & $0.12^{\star \star}$ & & 0.02 & & 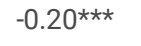 & & 0.03 & & -0.06 & & 0.05 \\
\hline Income & & 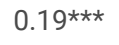 & & 0.07 & & 0.02 & & -0.02 & & 0.02 & & 0.07 \\
\hline Education & & -0.06 & & -.01 & & -0.08 & & -0.08 & & -0.05 & & -0.04 \\
\hline SSC & & $0.19 * \star \star$ & & $.19 * \star \star$ & & 0.02 & & 0.03 & & -0.09 & & $0.16^{\star \star \star}$ \\
\hline \multicolumn{13}{|c|}{ Note. $N=607$. SSC, subjective social class. } \\
\hline \multicolumn{13}{|l|}{${ }^{*} p<0.05$} \\
\hline \multicolumn{13}{|l|}{${ }^{* *} p<0.01$} \\
\hline$\star \star \star x p<0.001$ & & & & & & & & & & & & \\
\hline
\end{tabular}

In summary, the results of Study 1 were replicated in Study 2, in that those with high SC (mainly based on subjective measures) being more likely to use adaptive humor. There seemed to be no difference in the use of maladaptive humor based on SC. In summary, the results of Study 1 were replicated: hypotheses 1 and 3 were supported, while hypotheses 2 and 4 were not. Study 2, based on a larger sample, also did not support the results of the previous study ${ }^{11}$.

\section{General Discussion}

The present study was the first to examine the relationship between humor and SC by considering the many dimensions of humor, which has a multidimensional structure. We introduced and tested a new hypothesis about the relationship between SC and humor from the perspective of health behavior.

\subsection{SC and humor}

Our results generally supported the prediction (Hypotheses 1 and 2) that those with high SC would be more likely to engage in adaptive humor. That is, SC was found to be positively associated with affiliative humor and self-enhancing humor on the HSQ and with benign SDH on the DSDHS. Previous studies examining the association between SC and health behaviors ${ }^{32-38}$ have shown that people with high SC appear to engage in healthier behaviors. Healthy humor behaviors include telling jokes to entertain others and build relationships (affiliative humor), maintaining a joyful perspective on life (self-enhancing humor), and laughing at one's own misfortunes (benign SDH). It is noteworthy that throughout the two studies conducted in this study, we did not find any evidence of a positive association between SC and aggressive humor, as reported by previous studies ${ }^{11}$. In contrast, SC was positively associated with otheroriented humor, namely, affiliative humor. Although it is necessary to replicate these results in other future studies, our results seem to make more sense to us, given that the finding that people with high SC have low prosociality is currently being questioned. As Korndörfer et al. ${ }^{12}$ have argued, people with high SC may be more other oriented and altruistic. Our results do not support hypotheses 2 or 4 , indicating that maladaptive humor use is unrelated to an individual's SC. This result is not surprising given that those with low SC do not engage in all unhealthy behaviors ${ }^{33}$.

In this study, individual SC was measured using objective indicators, such as household income and educational attainment, and subjective indicators, such as perceived social status. The results that the objective measure of educational attainment was unrelated to humor are consistent with those of NavarroCarrillo et al. ${ }^{11}$. However, while Navarro-Carrillo et all ${ }^{11}$ reported that the objective measure, household income, showed the strongest link with humor, subjective SC showed a stronger association with humor in the present study. In the zero-order correlation analysis, both household income and subjective SC were associated with all adaptive humor, but when they were entered into the regression equation simultaneously, the effect of household income disappeared in many cases. This result is at odds with that of Navarro-Carrillo et al. ${ }^{11}$, who reported that income was more strongly linked to personal humor than subjective SC. However, in light of recent research claiming that subjective SC is a stronger predictor of psychology-related outcomes ${ }^{3}$, our results are more consistent with the findings of previous studies on SC.

\subsection{Contribution to the literature}

As noted at the outset, representative studies ${ }^{5,7}$ that claimed low prosociality in people with high SC have not been supported by subsequent replication studies $^{13,14}$, raising questions about the reliability of the theory and results. Therefore, the findings of low sociality among those with high SC, i.e., low 
compassion scores ${ }^{8}$, poor emotional reasoning by others ${ }^{9}$, and a lack of attention to others when meeting for the first time ${ }^{10}$, clearly require replication studies. This study contributes to the literature as one such study. Previous studies ${ }^{11}$ have shown that people with high SC engage in dominant and selfish aggressive humors, but this finding has not been replicated. In this study, we propose a new hypothesis on SC and humor from the viewpoint of health behavior and find that people with high SC engage in other-oriented and adaptive humor. This result is inconsistent with the findings of previous studies, which have claimed low prosociality among those with high SC, and rather shows that individuals with high SC appear to have high prosociality. It is recommended that other studies ${ }^{8-10}$ that have shown low prosociality in people with high SC continue to be replicated.

\subsection{Limitations}

There are several limitations to our study. The nonexperimental methodology used in the current study does not allow us to infer the direction of causality between constructs. In the regression equation, humor is predicted by SC, but this does not specify a causal relationship. In other words, we cannot rule out the possibility that SC is determined by an individual's use of humor. Alternative methodological approaches, such as longitudinal and experimental designs, should be implemented to uncover potential causal relationships between these constructs. It should also be noted that this study measures individual humor based solely on self-reported data. In general, adaptive humor is perceived as a desirable trait ${ }^{44}$, so social desirability may influence assessment. Therefore, it is useful to assign numerical scores of humor to individuals using peer assessment, observation, etc., and to confirm the reproducibility of the results. Moreover, since our sample was composed only of Japanese individuals, the conclusions may not be applicable to the general population as a whole. Therefore, it is desirable that the results be reproduced in specimens from other countries.

\subsection{Summary}

Previous studies on individual SC and humor ${ }^{11}$ hypothesized and supported a positive association between SC and dominant and selfish humor. This hypothesis was introduced based on the theory that people with high SC tend to be selfish ${ }^{27,28}$. However, this finding was not replicated in the two current studies; rather, it was shown that people with high SC engage in other-oriented and adaptive humor. The results of this study are consistent with those of recent studies ${ }^{13,14}$ that have raised questions about the finding that people with high $\mathrm{SC}$ have low prosociality. It is necessary that we accumulate research on SC and various psychological outcomes concerning propriety and draw clear conclusions on SC and prosociality.

\section{Declarations}

\section{Acknowledgements}

This work was supported by grant from the Japan Society for the Promotion of Science (JSPS KAKENHI, Grant Number JP21K02975).

\section{Author contributions}

R. T. - Conceptualization, Methodology, Formal Analysis, Investigation, Writing-Original Draft. T. I. - Methodology, Writing-Review and Editing. M. H. Methodology, Writing-Review and Editing.

\section{Data availability statement}

The data that support the findings of this study are openly available in Mendeley Data at https://doi.org/10.17632/v62t9z83xb.1.

\section{Competing interests}

The authors declare no competing interests.

\section{References}

1. Oakes, J. M. \& Rossi, P. H. The measurement of SES in health research: current practice and steps toward a new approach. Soc. Sci. Med. 56, 769-784 (2003)

2. Adler, N. E., Epel, E. S., Castellazzo, G. \& Ickovics, J. R. Relationship of subjective and objective social status with psychological and physiological functioning: preliminary data in healthy, White women. Health Psychol. 19, 586-592 (2000).

3. Kraus, M. W., Piff, P. K. \& Keltner, D. Social class, sense of control, and social explanation. J. Pers. Soc. Psychol. 97, 992-1004 (2009).

4. Guinote, A., Cotzia, I., Sandhu, S. \& Siwa, P. Social status modulates prosocial behavior and egalitarianism in preschool children and adults. Proc. Natl. Acad. Sci. U.S.A. 112, 731-736 (2015).

5. Piff, P. K., Kraus, M. W., Côté, S., Cheng, B. H. \& Keltner, D. Having less, giving more: the influence of social class on prosocial behavior. J. Pers. Soc. Psychol. 99, 771-784 (2010).

6. Dubois, D., Rucker, D. D. \& Galinsky, A. D. Social class, power, and selfishness: when and why upper and lower class individuals behave unethically. J. Pers. Soc. Psychol. 108, 436-449 (2015).

7. Piff, P. K., Stancato, D. M., Côté, S., Mendoza-Denton, R. \& Keltner, D. Higher social class predicts increased unethical behavior. Proc. Natl. Acad. Sci. U.S.A. 109, 4086-4091 (2012).

8. Stellar, J. E., Manzo, V. M., Kraus, M. W. \& Keltner, D. Class and compassion: socioeconomic factors predict responses to suffering. Emotion 12, 449-459 (2012).

9. Kraus, M. W., Côté, S. \& Keltner, D. Social class, contextualism, and empathic accuracy. Psychol. Sci. 21, 1716-1723 (2010). 
10. Kraus, M. W. \& Keltner, D. Signs of socioeconomic status. Psychol. Sci. 20, 99-106 (2009).

11. Navarro-Carrillo, G., Torres-Marín, J. \& Carretero-Dios, H. Class-based differences in the use of (aggressive) humor: the mediating role of empathic concern. Pers. Individ. Differ. 159, 109868 (2020).

12. Korndörfer, M., Egloff, B. \& Schmukle, S. C. A large scale test of the effect of social class on prosocial behavior. PLoS One 10, e0133193 (2015).

13. Stamos, A., Lange, F., Huang, S. c. \& Dewitte, S. Having less, giving more? Two preregistered replications of the relationship between social class and prosocial behavior. J. Res. Pers. 84, 103902 (2020).

14. Balakrishnan, A., Palma, P. A., Patenaude, J. \& Campbell, L. A 4-study replication of the moderating effects of greed on socioeconomic status and unethical behaviour. Sci. Data 4, 160120 (2017).

15. Andreoni, J., Nikiforakis, N. \& Stoop, J. Are the rich more selfish than the poor, or do they just have more money? A natural field experiment. National Bureau of Economic Research. https://www.nber.org/papers/w23229 (2017).

16. Liebe, U. \& Tutic, A. Status groups and altruistic behaviour in dictator games. Ration. Soc. 22, 353-380 (2010).

17. Takebe, M. \& Murata, K. The influence of subjective socioeconomic status on helping intention. J. Hum. Environ. Stud. 14, 93-99 (2016).

18. Tutić, A. \& Liebe, U. Contact heterogeneity as a mediator of the relationship between social class and altruistic giving. Socius 6,237802312096933 (2020)

19. Martin, R. A., Puhlik-Doris, P., Larsen, G., Gray, J. \& Weir, K. Individual differences in uses of humor and their relation to psychological well-being: development of the humor styles questionnaire. J. Res. Pers. 37, 48-75 (2003).

20. Martin, R. A. On the challenges of measuring humor styles: Response to Heintz and Ruch. Humor $\mathbf{2 8 < b v e r t i c a l - a l i g n : s u p e r ; > , < / b v e r t i c a l - a l i g n : s u p e r ; > ~}$ 635-639 (2015)

21. Tsukawaki, R. \& Imura, T. The light and dark side of self-directed humor: the development and initial validation of the Dual Self-Directed Humor Scale (DSDHS). Pers. Individ. Differ. 157, 109835 (2020).

22. Allport, G. W. Pattern and growth in personality (Holt, Rinehart \& Winston, 1961).

23. Maslow, A. H. Motivation and personality (Harper \& Row, 1954).

24. McGhee, P. E. Humor as survival training for a stressed-out world: the 7 humor habits program (AuthorHouse IN, 2010).

25. Ziv, A. Personality and sense of humor (Springer, 1984).

26. Tsukawaki, R. \& Imura, T. Incremental validity of the dual self-directed humor scale in predicting psychological well-being: beyond the big five personality traits and four humor styles. Curr. Psychol. 10.1007/s12144-021-01596-9 (2021).

27. Kraus, M. W., Piff, P. K., Mendoza-Denton, R., Rheinschmidt, M. L. \& Keltner, D. Social class, solipsism, and contextualism: how the rich are different from the poor. Psychol. Rev. 119, 546-572 (2012).

28. Piff, P. K. Wealth and the inflated self. Pers. Soc. Psychol. Bull. 40, 34-43 (2014).

29. Chen, B., Zuo, Y. \& Zhao, Y. The relationship between subjective social class and aggression: a serial mediation model. Pers. Individ. Differ. 131, 174-179 (2018).

30. Greitemeyer, T. \& Sagioglou, C. Subjective socioeconomic status causes aggression: a test of the theory of social deprivation. J. Pers. Soc. Psychol. 111, 178-194 (2016).

31. Gochman, D. S. Handbook of health behavior research I: personal and social determinants (Plenum Press, 1997).

32. Hiscock, R., Bauld, L., Amos, A., Fidler, J. A. \& Munafò, M. Socioeconomic status and smoking: a review. Ann. N. Y. Acad. Sci. 1248, 107-123 (2012).

33. Moore, G. F. \& Littlecott, H. J. School- and family-level socioeconomic status and health behaviors: multilevel analysis of a national survey in wales, United Kingdom. J. Sch. Health 85, 267-275 (2015).

34. Mulder, B. C., de Bruin, M., Schreurs, H., van Ameijden, E. J. C. \& van Woerkum, C. M. J. Stressors and resources mediate the association of socioeconomic position with health behaviours. BMC Public Health 11, 798-798 (2011).

35. Nandi, A., Glymour, M. M. \& Subramanian, S. V. Association among socioeconomic status, health behaviors, and all-cause mortality in the United States. Epidemiology 25, 170-177 (2014).

36. Stringhini, S. et al. Association of socioeconomic position with health behaviors and mortality. JAMA 303, 1159-1166 (2010).

37. Svendsen, M. T. et al. Associations of health literacy with socioeconomic position, health risk behavior, and health status: a large national populationbased survey among Danish adults. BMC Public Health 20, 565 (2020).

38. Valencia, M. L. C., Tran, B. T., Lim, M. K., Choi, K. S. \& Oh, J. K. Association between socioeconomic status and early initiation of smoking, alcohol drinking, and sexual behavior among Korean adolescents. Asia Pac. J. Public Health 31, 443-453 (2019).

39. Schneider, M., Voracek, M. \& Tran, U. S. "A joke a day keeps the doctor away?" Meta-analytical evidence of differential associations of habitual humor styles with mental health. Scand. J. Psychol. 59, 289-300 (2018).

40. Heintz, S. \& Ruch, W. From four to nine styles: an update on individual differences in humor. Pers. Individ. Differ. 141, 7-12 (2019).

41. Yoshida, K. Nihongoban yumoa sutairu shitsumonshi no sakusei [Development of the Japanese version of the revised death anxiety scale]. Jpn. Soc. Laugh. Humour Stud. 19, 56-66 (2012).

42. Akinwande, M. O., Dikko, H. G. \& Samson, A. Variance inflation factor: as a condition for the inclusion of suppressor variable(s) in regression analysis. Open J. Stat. 5, 754-767 (2015).

43. American Psychological Association. Report of the APA task force on socioeconomic status (American Psychological Association, 2007).

Page 9/10 
44. Martin, R. A. The psychology of humor: an integrative approach (Elsevier Academic Press, 2007).

Page $10 / 10$ 